\title{
A influência da propriedade, gestão e controle familiar no gerenciamento de resultados de empresas brasileiras listadas na B3
}

\section{The influence of ownership, management and family control on earnings management of Brazilian companies listed on B3}

\author{
JULIANO FRANCISCO BALDISSERA \\ Universidade Estadual de Maringá (UEM) \\ IVAN RAFAEL DEFAVERI \\ Universidade Estadual de Maringá (UEM) \\ DENIS DALL'ASTA \\ Universidade Estadual do Oeste do Paraná (Unioeste) \\ CLÓVIS FIIRST \\ Universidade Estadual do Oeste do Paraná (Unioeste)
}

\section{RESUMO}

O objetivo desta pesquisa foi de verificar a influência da propriedade, gestão e controle familiar na prática de gerenciamento de resultados das empresas brasileiras listadas na B3. Adotou-se uma abordagem quantitativa, utilizando-se do modelo de Kang e Sivaramakrishnan (1995) para mensurar os accruals discricionários, realizando-se a análise a partir de testes de estatística descritiva, correlação e regressão linear múltipla. Os dados foram obtidos da Economática $\odot$, somando o total de 207 empresas, das quais 80 eram de propriedade familiar, enquanto 77 obtinham a gestão familiar e 55 o controle familiar, abrangendo um período de seis anos. Os resultados da pesquisa permitiram observar que as empresas de propriedade, gestão e controle familiar apresentam menores níveis de gerenciamento de resultados do que as empresas não familiares, sendo esta diferença estatisticamente significante. A segregação das empresas familiares em propriedade, gestão e controle familiar, permitiu verificar que somente as companhias cujo controle é familiar tem relação negativa com 
os níveis de gerenciamento de resultados. O custo de agência é reduzido pela presença do controle familiar, levando a menores índices de gerenciamento e melhor qualidade dos lucros. Essas entidades evitam ações que prejudicam o valor futuro devido à preocupação na sustentabilidade transgeracional.

Palavras chave: Empresas familiares; Gerenciamento de Resultados; Socioemotional Wealth Theory; Teoria da Agência

\section{Abstract}

The purpose of this research was to verify the influence of ownership, management and family control on the practice of earnings management of Brazilian companies listed on the B3. A quantitative approach was adopted, using the Kang and Sivaramakrishnan (1995) model to measure discretionary accruals, and the analysis was based on descriptive statistics, correlation and multiple linear regression tests. The data were obtained from Economática(C), totaling 207 companies, 80 of which were family owned, while 77 obtained family management and 55 family control, covering a period of six years. The results of the research allowed us to observe that family ownership, management and control companies have lower levels of earnings management than non-family companies, and this difference is statistically significant. The segregation of family businesses in family ownership, management and control has allowed us to verify that only companies whose family control is negatively related to the levels of earnings management. The cost of agency is reduced by the presence of family control, leading to lower management rates and better quality of profits. These entities avoid actions that jeopardize the future value due to concern in transgenerational sustainability.

Keywords: Family businesses; Earnings Management; Socioemotional Wealth Theory; Agency Theory.

\section{INTRODUÇÃo}

As empresas familiares enfrentam conflitos e realidades diferenciadas na gestão de suas organizações. A Socioemotional Wealth Theory argumenta que os membros da família consideram as questões econômicas em termos de como suas ações afetarão sua dotação socioeconômica (ACHLEITNER; GÜNTHER; KASERER; SICILIANO, 
2014). Essa teoria discute a noção de que as famílias tomam suas decisões considerando fatores que podem afetar o seu valor futuro, visto a preocupação em manter a empresa para as gerações futuras, o que suscita a ideia de que manipulam os resultados de modo que a empresa se mantenha estável e não perca valor (GÓMEZ-MEJÍA et al., 2007; BERRONE; CRUZ; GOMEZ-MEJIA, 2012; ACHLEITNER et al., 2014).

Evidências empíricas recentes têm demonstrado que as empresas familiares são menos propensas a praticarem o gerenciamento de resultados (VIEIRA, 2016), no entanto, pesquisas também indicam o fato de a propriedade familiar afetar no desempenho das empresas e na qualidade das informações (JAGGI; LEUNG; GUL, 2009).

Existem várias formas de se avaliar essa qualidade da informação, como conservadorismo, tempestividade, oportunidade, relevância, pertinência e também o gerenciamento de resultados (FASOLIN; KLAN, 2015). Essa prática do gerenciamento de resultados tem sido um tema recorrente nas pesquisas na área da contabilidade financeira (PRENCIPE; MARKARIAN; POZZA, 2008), devido essa prática representar distorções na qualidade das informações e ocasionar problemas de agência (HEALY; WAHLEN, 1999; SETIA-ATMAJA; HAMAM; TANEWSKI, 2011).

Tal prática geralmente é realizada por gestores que pretendem distorcer as informações repassadas ao mercado, alterando as demonstrações contábeis, para se beneficiarem em transações e contratos (HEALY; WAHLEN, 1999; SETIA-ATMAJA; HAMAM; TANEWSKI, 2011). As pesquisas nessa área, contudo, tendem a se concentrar em empresas abertas (PRENCIPE; MARKARIAN; POZZA, 2008; ALMEIDA-SANTOS; DANI; MACHADO; KRESPI, 2013), não explorando as diferenças do comportamento de gestores quanto a essas práticas em empresas familiares e não-familiares (VIEIRA, 2016).

O fato de as empresas serem de propriedade familiar pode fazer com que o comportamento dos gestores em relação a prática de gerenciamento de resultados seja diferente das demais empresas (JIRAPORN; DATALT, 2007), de modo às evidencias empíricas indicarem que a propriedade familiar tende a reduzir os efeitos da prática de gerenciamento de resultados nas empresas (ALI; CHEN; 
RADHAKRISHNAN, 2007; PRENCIPE; MARKARIAN; POZZA, 2008; JAGGI; LEUNG; GUL, 2009; VIEIRA, 2016).

Em busca de avançar as discussões e a compreensão a respeito da relação entre a propriedade familiar e o gerenciamento de resultados, outros estudos pesquisaram aprofundadamente essa relação (ALI; CHEN; RADHAKRISHNAN, 2007; PRENCIPE; MARKARIAN; POZZA, 2008; JAGGI; LEUNG; GUL, 2009; SETIA-ATMAJA; HAMAM; TANEWSKI, 2011; ALMEIDA-SANTOS et al., 2013; LI; HUNG, 2013). Entretanto, apenas o estudo de Almeida-Santos et al. (2013) focou o contexto brasileiro, não tratando, contudo, a propriedade, gestão e controle familiar de maneira diferenciada, além de não discutir alguns aspectos relevantes nas empresas familiares, como o tamanho, alavancagem, rentabilidade, idade, governança corporativa e setor.

Além disso, as empresas familiares retratam uma realidade diferenciada, já que os conflitos de agência também afetam o desempenho destas empresas, mas tendem a ser menores em empresas familiares do que em não familiares, pois o controle da gestão geralmente é realizado pela família (SCHULZE; LUBATKIN; DINO; BUCHHOLTZ, 2001; SETIA-ATMAJA; HAMAM; TANEWSKI, 2011). Entretanto, as empresas familiares podem obter concentração acionária, tendo o poder de buscar benefícios próprios em detrimentos de outros acionistas minoritários (GILSON; GORDON, 2003).

Assim, como forma de direcionar o presente estudo, foi elaborado como questão de pesquisa: Qual a influência da propriedade, gestão e controle familiar na prática de gerenciamento de resultados das empresas brasileiras listadas na B3? Para responder a essa questão, foi determinado como objetivo da pesquisa verificar a influência da propriedade, gestão e controle familiar na prática de gerenciamento de resultados das empresas brasileiras listadas na B3.

Assim, este estudo se mostra inicial e diferente das demais pesquisas nacionais e internacionais, já que além de discutir o comportamento de gerenciamento de resultados nas empresas familiares, fará a distinção entre a propriedade, gestão e controle familiar, associada a aspectos (tamanho, alavancagem, rentabilidade, idade, governança corporativa e setor) que podem impactar a qualidade da informação contábil que estas empresas têm divulgado. 
Desse modo, para atender aos objetivos propostos, a presente pesquisa se divide, além da presente introdução, no referencial teórico, que trata conceitos e discussões acerca da propriedade, gestão e controle familiar a prática de gerenciamento de resultados, além de estudos anteriores que fundamentam as hipóteses de pesquisa. Também conta com a metodologia, em que são apresentados os métodos utilizados para análise dos dados, e, por fim, a apresentação e discussão dos resultados e conclusões do estudo.

\section{REFERENCIAL TEÓRICO}

\subsection{Propriedade, Gestão e Controle Familiar}

Empresas familiares são aquelas constituídas por dois ou mais membros de uma mesma família, que são donos ou gerenciam a empresa em conjunto ou por sucessão, bem como são consideradas assim quando a propriedade da empresa passa de uma geração para outra de uma mesma família (LONGENECKER; MOORE; PETTY, 2007; SEGURA; FORMIGONI, 2014).

Existe, no entanto, uma distinção entre propriedade e controle, conforme indicado pelo trabalho seminal de Berle e Means (1932), que indica o fato de o fator distintivo das corporações modernas ser a divisão da propriedade, que pode ser dividida entre diversos acionistas, e o controle, onde uma pessoa ou um pequeno grupo detêm uma parcela das ações considerável para o comando da companhia (ALDRIGHI; MAZZER NETO, 2005).

No contexto das empresas familiares, a propriedade familiar ocorre quando a totalidade do capital da empresa é detido pelos membros um mesmo grupo familiar (SEGURA, 2011) ou ao menos dois membros de uma mesma família detenham ações (FIEGENER, 2010) , já o controle familiar ocorre quando os membros da família têm ao menos $20 \%$ do total das ações com direito a voto da companhia (LEAL; SILVA; VALADARES, 2002), não havendo outros acionistas com percentuais acionários maiores, ou então, quando dois ou mais membros da família possuem o controle de mais de 50\% do total das ações (THOMSEN; PEDERSEN, 1997).

Existe ainda um terceiro tipo de influência familiar dentro das companhias, que é a gestão familiar, que se difere da propriedade 
e do controle familiar pelo fato de os membros da família não possuírem ações o suficiente para deterem o controle, mas os membros da família ocupam os cargos de alta gerência (SEGURA, 2011).

Desse modo, apesar de a maioria dos estudos costumar não apresentar uma classificação distinta para a propriedade, controle e gestão familiar (SEGURA, 2011; SEGURA; FORMIGONI, 2014; VIEIRA, 2016), indicando as empresas apenas como familiares, nota-se que essas três categorias de empresas familiares (propriedade, controle e gestão), exercem influências distintas na realidade das empresas (THOMSEN; PEDERSEN, 1997).

Empresas cuja família detenha o controle acionário tendem a escolher os gestores, se não membros da família, que tenham relacionamento próximo com a mesma, de modo a gerenciar a companhia de acordo com a visão de longo prazo da família (PRENCIPE; MARKARIAN; POZZA, 2008). Nessas situações, a tendência é que os problemas de agência sejam reduzidos, uma vez que existe o alinhamento entre os interesses da família controladora e dos gestores (SETIA-ATMAJA; HAMAM; TANEWSKI, 2011), no entanto, essa relação pode levar ao aumento do conflito de agência entre os interesses dos controladores e dos acionistas não membros da família (PORTA; LOPEZ-DE-SILANES; SHLEIFER; VISHNY, 1998), uma vez que nesses casos a gestão da empresa tende a corresponder aos objetivos e visões da família, e não necessariamente à busca do desempenho global da companhia (YOUNG; PENG; AHLSTROM; BRUTON; JIANG, 2008).

Nos casos onde a propriedade da empresa corresponde ao grupo familiar, no entanto as ações estão pulverizadas entre um grande número de acionistas, que não necessariamente detém o controle da companhia, e a gestão é exercida por um gestor profissional, não membro da família nem com forte influência na mesma, a tendência é que o foco da gestão não seja totalmente concentrado na visão da família, mas sim no desempenho da empresa (SEGURA, 2011).

Essas situações de conflito acabam por influenciar na prática do gerenciamento de resultados das companhias (FASOLIN; KLANN,2015) de modo a essa prática apresentar distinções nesse tipo de empresas em relação as empresas não familiares (SETIA-ATMAJA; HAMAM; TANEWSKI, 2011). 


\subsection{Gerenciamento de Resultados}

A prática do gerenciamento de resultados pode ser definida como a manipulação de informações por gestores, que utilizam o julgamento pessoal para determinar operações e estruturação de demonstrativos contábeis (HEALY; WAHLEN, 1999), para, dessa forma, alterar a percepção dos investidores com relação a real situação financeira da empresa (MARTINEZ, 2013).

O conceito dessa prática deriva da teoria da agência proposta por Jensen e Meckling (1976), de modo a ser uma prática que expõe a relação entre os interesses de principais e agentes (ALMEIDA-SANTOS et al., 2013). Dechow, Sloan e Sweeney (1996) indicam o fato de essa técnica ser utilizada por gestores com o intuito de trazer investidores para a companhia, ao indicar uma situação econômica superior.

A abordagem clássica para o estudo do gerenciamento de resultados se concentra na análise dos accruals, que representam a diferença entre o fluxo de caixa das operações e o resultado contábil (CUPERTINO; MARTINEZ, 2008). Existem duas abordagens dos accruals, sendo aqueles relativos a práticas e convenções definidas por normas contábeis, e outra, a dos chamados accruals discricionários, onde as ações decorrem tão somente da vontade dos gestores (CUPERTINO; MARTINEZ, 2008). Existem diversos modelos na teoria utilizados para medir essa prática, dos quais destacam-se o modelo Jones (1991), Dechow, Sloan e Sweeney (1996), Paulo (2007), sendo o modelo aplicado neste estudo o modelo de Kang e Sivaramakrishnan (1995), também conhecido como modelo KS (ALMEIDA-SANTOS et al., 2013).

Nas empresas com controle acionário nas mãos dos membros de uma mesma família, em que a gestão seja exercida por membros da família ou gestores próximos a ela, existe a tendência ao gerenciamento de resultados ocorrer de forma menos intensa que em empresas não familiares (LI; HUNG, 2013), pois essas empresas costumam apresentar um maior alinhamento entre a ação dos gestores e os interesses da organização (VIEIRA, 2016). Em comparação as ideias de Dechow, Sloan e Sweeney (1996), essa tendência se mostra reduzida tendo em vista o fato de, como a família detém o controle acionário, não haver a necessidade de trazer outros investidores com intuito de assumirem a propriedade da empresa. 
Outro fator que influencia a pratica do gerenciamento de resultados ser menos corriqueira nas empresas familiares é o maior conhecimento das atividades exercidas, de modo à família poder fiscalizar de forma mais efetiva a ação dos gestores (ALI; CHEN; RADHAKRISHNAN, 2007).

No entanto, a literatura não traz um consenso sobre o fato de as empresas familiares gerenciarem menos os seus resultados (SETIA-ATMAJA; HAMAM; TANEWSKI, 2011). Isso se dá pelo fato de a família optar por gestores membros ou próximos da família, bem como o controle familiar levar a família a ditar os rumos da companhia, de modo a aumentar a distância informacional entre os gestores e os demais acionistas da empresa, não componentes do grupo familiar (ANDERSON; REEB, 2004).

Essa relação entre as práticas de gerenciamento de resultados em empresas familiares já foi discutida em diversos estudos, como por exemplo Ali, Chen e Radhakrishnan (2007), Prencipe e Markarian e Pozza (2008), Jaggi, Leung e Gul (2009), Setia-Atmaja, Hamam e Tanewski (2011), Almeida-Santos et al. (2013), Li e Hung (2013), Fasolin e Klann (2015) e Vieira (2016), os quais são apresentados para construção das hipóteses de pesquisa.

\subsection{Estudos Anteriores e Hipóteses da Pesquisa}

Diversos estudos já investigaram a relação entre a propriedade familiar de empresas e a prática do gerenciamento de resultados. Dentre esses estudos destaca-se o de Ali, Chen e Radhakrishnan (2007). Os autores buscaram em sua pesquisa identificar como o fato de a empresa ser familiar ou não familiar pode influenciar no gerenciamento de resultado das firmas americanas. Para isso, os autores consideram a diferenciação entre os dois tipos de problema de agência. $O$ problema de tipo I, que ocorre entre os proprietários e gestores, o qual os autores indicam ser menos recorrente nas empresas familiares, e também o problema do tipo II, que ocorre entre acionistas controladores e não controladores, o qual é mais frequente e grave nas empresas familiares.

Para tanto, os autores realizaram uma pesquisa com as empresas componentes da Standard \& Poor's 500, através da captação de informações divulgadas por essas empresas no período entre 1998 
e 2002, tratados através da modelagem de dados em painel. Os resultados alcançados confirmam a literatura utilizada como base, indicando para o fato de as empresas familiares apresentarem menos problemas de agência do tipo I e mais problemas de agência do tipo II em relação as empresas não-familiares.

Outro estudo que buscou tratar dessa relação foi o de Prencipe, Markarian e Pozza (2008). Nessa pesquisa, os autores buscaram identificar como funciona a prática do gerenciamento de resultados em empresas familiares listas em bolsa de valores, de forma a comparar com a prática em empresas listadas não familiares. Para tanto, os autores focaram em empresas do ramo de pesquisa e desenvolvimento listadas na bolsa de valores de Milão. Os achados da pesquisa indicam que as empresas familiares são menos sensíveis do que as não familiares em flutuações de curto prazo do mercado, de modo a gerenciarem menos seus resultados, uma vez que tem como foco manter a saúde do negócio, ao invés de maximizar as riquezas dos acionistas no curto prazo.

No estudo de Jaggi, Leung e Gul (2009) os autores buscaram identificar como a presença de membros da família no conselho de administração das companhias pode interferir na prática do gerenciamento de resultados. Os resultados da pesquisa indicaram que, em firmas de Hong Kong, a inserção de membros externos à família nos conselhos de administração auxilia na redução do gerenciamento de resultados, mas não contribui efetivamente no monitoramento dessa prática.

Uma pesquisa semelhante foi realizada por Setia-Atmaja, Hamam e Tanewski (2011), com foco nas empresas listadas na Austrália, cujos resultados corroboraram com os de Jaggi, Leung e Gul (2009), ao indicar que, em empresas controladas por famílias, a presença de membros externos no conselho de administração reduz consideravelmente a realização dos gerenciamentos de resultados, bem como que os gestores dessas empresas tendem a ser menos agressivos no que diz respeito a realização de gerenciamento de resultados por accruals discricionários.

No contexto brasileiro, o estudo de Almeida-Santos et al. (2013) teve como intuito identificar se o controle acionário familiar influencia negativamente o gerenciamento de resultados e se isso 
pode piorar os lucros contábeis das companhias. Os resultados indicam o fato de as empresas brasileiras com controle familiar apresentarem índices de lucratividade menores, mas que mostram um maior número de accruals discricionários do que as empresas não familiares.

Ainda no contexto do Brasil, o estudo de Fasolin e Klann (2015) avaliou a utilização de accruals específicos por empresas familiares. Os resultados da pesquisa indicam para o fato de haver indícios de gerenciamento de resultados nas empresas familiares, no entanto não foi possível identificar diferenças de comportamento entre as empresas familiares e as não familiares.

Por fim, o estudo de Vieira (2016) investigou se existem diferenças no comportamento das empresas familiares e não familiares no que tange a prática do gerenciamento de resultados. Também investigou se existe diferenças no comportamento das empresas quanto ao gerenciamento de resultados em períodos de estabilidade ou instabilidade econômica, no contexto das empresas de Portugal. O estudo não encontrou diferenças significativas nesse comportamento entre as empresas familiares e não familiares. No entanto, as empresas familiares mostram-se menos suscetíveis a gerir seus resultados em decorrência da sua orientação de longo prazo e da necessidade de garantir a propriedade da empresa para sucessores familiares.

Dessa forma, com base nesses estudos, apesar de existir resultados cuja relação foi positiva (Almeida-Santos et al., 2013), enquanto outros não puderam confirma essa associação (Fasolin \& Klann, 2015; Vieira, 2016), a maior parte da literatura confirma uma relação negativa (Ali, Chen \& Radhakrishnan, 2007; Prencipe, Markarian \& Pozza, 2008; Jaggi, Leung \& Gul, 2009; Setia-Atmaja, Hamam \& Tanewski, 2011), formulou-se as seguintes hipóteses de pesquisa, que guiam a análise dos dados:

H1 - A propriedade familiar influencia nagativamente os accruals discricionários das empresas brasileiras listadas B3

H2 - A gestão familiar influencia nagativamente os accruals discricionários das empresas brasileiras listadas B3 
H3 - O controle familiar influencia nagativamente os accruals discricionários das empresas brasileiras listadas B3

Feita essas considerações e apresentada as hipóteses, a próxima seção descreve o delineamento metodológico adotado nesta pesquisa.

\section{METODOLOGIA}

Tendo em vista o objetivo de verificar a influência da propriedade, gestão e controle familiar na prática de gerenciamento de resultados das empresas brasileiras listadas na B3, delineou-se esta pesquisa a partir de uma abordagem quantitativa, por meio de um estudo empírico, com o emprego de instrumentos estatísticos no tratamento dos dados.

A amostra é não probabilística escolhida de forma não intencional e não aleatória, compreendeu as companhias brasileiras não financeiras listadas na B3, abrangendo um período de seis anos. Assim, foi possível obter 207 empresas, sendo: 80 de propriedade familiar (40\%) e 127 de propriedade não familiar (60\%); 77 de gestão familiar (37\%) e 130 de gestão não familiar (63\%); 55 de controle familiar (26\%) e 152 de controle não familiar (74\%). Além disso, apesar de não se obter dados do período mais recente, o que se espera inferir nesse estudo é o efeito da família no gerenciamento de resultados, independentemente do momento no tempo analisado.

Os dados financeiros destas entidades foram obtidos a partir da base de dados da Economática ${ }^{\circledR}$, além do próprio site da B3 por meio das Demonstrações Financeiras Padronizados (DFPs).

O modelo utilizado para o cálculo dos accruals discricionários (gerenciamento de resultados) foi o modelo econométrico proposto por Kang e Sivaramakrishnan - KS (1995). O modelo KS é um dos modelos mais robustos, tanto no sentido contábil de descrever mais eficientemente o processo de definição das acumulações, como no aspecto relacionado à precisão estatística (HEALY; WAHLEN, 1999; MARTINEZ, 2001). Na equação 1, apresenta-se o modelo: 


$$
\frac{A B_{t}}{A T_{t-1}}=\beta_{0}+\beta_{1}\left[\frac{\delta_{1} R E V_{t}}{A T_{t-1}}\right]+\beta_{2}\left[\frac{\delta_{2} E X P_{t}}{A T_{t-1}}\right]+\beta_{3}\left[\frac{\delta_{3} G P P E_{t}}{A T_{t-1}}\right]+\varepsilon
$$

Sendo:

Equação (1)

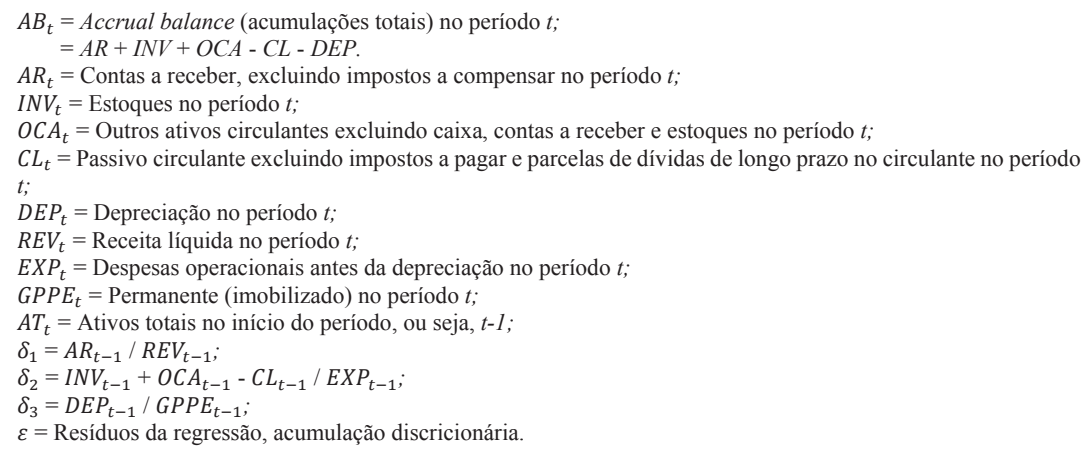

Para realizar os testes das hipóteses H1, H2 e H3 foi necessário delimitar as empresas de propriedade, gestão e controle familiar. Os estudos que fazem a diferenciação da característica familiar na empresa são diversos e controversos, já que ora tratam o controle familiar, ora apenas a descrição de empresa familiar e, por outras vezes, a família na gestão ou nas ações da empresa (SEGURA; FORMIGONI, 2014).

Assim, classificou-se essas empresas de acordo com o estudo de Segura (2011) e Segura e Formigoni (2014): empresas familiares quando dois ou mais diretores de uma mesma família na administração da empresa ou dois ou mais diretores de uma mesma família que possuem ações da empresa - independentemente do número de ações; gestão familiar são as empresas familiares que possuem também pessoas da família nos cargos de comando da empresa, independentemente de haver controle acionário; controle familiar quando além de serem classificadas como familiares, os acionistas familiares possuem mais de $50 \%$ das ações da companhia. Portanto, utilizou-se uma variável dummy para operacionalização da variável que representa a característica familiar, propriedade/gestão/controle familiar " 1 ", propriedade/gestão/controle não familiar " 0 ".

Além das variáveis que caracterizam a propriedade, gestão e controle familiar, tem-se as variáveis explicativas do gerenciamento de resultados. A Tabela 1 evidencia as variáveis independentes, res- 
pectivas descrições e a relação esperada de cada uma das variáveis em função do nível de accruals discricionários (AD), de acordo as evidências de estudos anteriores

Tabela 1 - Variáveis da pesquisa

\begin{tabular}{|c|c|c|c|}
\hline Variáveis & $\begin{array}{l}\text { Mensu- } \\
\text { ração }\end{array}$ & Descrição & Evidências \\
\hline \multirow{2}{*}{$\begin{array}{l}\text { Empresa } \\
\text { Familiar } \\
\text { (Efam) }\end{array}$} & 1 & $\begin{array}{l}\text { Se há dois ou mais diretores de } \\
\text { uma mesma família na administra- } \\
\text { ção da empresa ou dois ou mais } \\
\text { diretores de uma mesma família } \\
\text { que possuem ações da empresa. }\end{array}$ & \multirow{6}{*}{$\begin{array}{l}\text { Mallorquí } \\
\text { et al. (2007); } \\
\text { Prencipe, } \\
\text { Markarian } \\
\text { e Pozza } \\
\text { (2008); Jaggi, } \\
\text { Leung e Gul } \\
\text { (2009); Ishak } \\
\text { et al. (2011); } \\
\text { Setia-Atma- } \\
\text { ja, Hamam } \\
\text { e Tanewski } \\
\text { (2011); Al- } \\
\text { meida-Santos } \\
\text { et al. (2013). }\end{array}$} \\
\hline & 0 & $\begin{array}{l}\text { Se não há dois ou mais diretores } \\
\text { de uma mesma família na admi- } \\
\text { nistração da empresa ou dois ou } \\
\text { mais diretores de uma mesma } \\
\text { família que possuem ações da } \\
\text { empresa. }\end{array}$ & \\
\hline \multirow{2}{*}{$\begin{array}{l}\text { Gestão } \\
\text { Familiar } \\
\text { (Gfam) }\end{array}$} & 1 & $\begin{array}{l}\text { Se além de caracterizar ser uma } \\
\text { empresa familiar e possuir tam- } \\
\text { bém pessoas da família nos cargos } \\
\text { de comando da empresa. }\end{array}$ & \\
\hline & 0 & $\begin{array}{l}\text { Se não caracterizar ser uma em- } \\
\text { presa familiar e possuir também } \\
\text { pessoas da família nos cargos de } \\
\text { comando da empresa. }\end{array}$ & \\
\hline \multirow{2}{*}{$\begin{array}{l}\text { Controle } \\
\text { Familair } \\
\text { (Cfam) }\end{array}$} & 1 & $\begin{array}{l}\text { Se além de serem classificadas } \\
\text { como familiares, os acionistas } \\
\text { familiares possuírem mais de } 50 \% \\
\text { das ações da companhia. }\end{array}$ & \\
\hline & 0 & $\begin{array}{l}\text { Se não serem classificadas como } \\
\text { familiares e os acionistas familia- } \\
\text { res não possuírem mais de } 50 \% \\
\text { das ações da companhia. }\end{array}$ & \\
\hline $\begin{array}{l}\text { Tamanho } \\
\text { (TAM) }\end{array}$ & $\begin{array}{l}\text { Log } \\
\text { (Ativo } \\
\text { Total) } \\
\end{array}$ & $\begin{array}{l}\text { Representada pelo Logaritmo } \\
\text { Natural do ativo da empresa } i \text { no } \\
\text { ano } t \text {. }\end{array}$ & $\begin{array}{l}\text { Jaggi, Leung } \\
\text { e Gul (2009) }\end{array}$ \\
\hline
\end{tabular}




\begin{tabular}{|c|c|c|c|c|}
\hline $\begin{array}{l}\text { Alavan- } \\
\text { cagem } \\
(\mathrm{ALA})\end{array}$ & & $\begin{array}{l}\text { Representada pela razão entre o } \\
\text { Passivo Total e o Ativo Total da } \\
\text { empresa } i \text { no ano } t \text {. }\end{array}$ & + & $\begin{array}{l}\text { Coelho e Lo- } \\
\text { pes (2007) }\end{array}$ \\
\hline $\begin{array}{l}\text { Retorno } \\
\text { sobre o } \\
\text { patri- } \\
\text { mônio } \\
\text { líquido } \\
\text { (ROE) } \\
\end{array}$ & & $\begin{array}{l}\text { Representada pela razão entre o } \\
\text { Lucro Líquido e o Patrimônio Lí- } \\
\text { quido da empresa } i \text { no ano } t \text {. }\end{array}$ & + & $\begin{array}{l}\text { Liu e Lu } \\
(2007)\end{array}$ \\
\hline $\begin{array}{l}\text { Retorno } \\
\text { sobre o } \\
\text { ativo } \\
\text { (ROA) }\end{array}$ & & $\begin{array}{l}\text { Representada pela razão entre o } \\
\text { Lucro Líquido e o Ativo Total da } \\
\text { empresa } i \text { no ano } t \text {. }\end{array}$ & + & $\begin{array}{l}\text { Prencipe, } \\
\text { Markarian e } \\
\text { Pozza (2008), } \\
\text { Jaggi, Leung } \\
\text { e Gul (2009) }\end{array}$ \\
\hline $\begin{array}{l}\text { Idade da } \\
\text { empresa } \\
\text { (IDA) }\end{array}$ & & $\begin{array}{l}\text { Idade que a empresa faz parte na } \\
\text { bolsa de valores (BMF\&BOVESPA). }\end{array}$ & - & $\begin{array}{l}\text { Ahmad- } \\
\text {-Zaluki et al. } \\
(2009)\end{array}$ \\
\hline \multirow{2}{*}{$\begin{array}{l}\text { Gover- } \\
\text { nança } \\
(\text { GOV) }\end{array}$} & 1 & $\begin{array}{l}\text { Se a empresa está em um dos } \\
\text { níveis de governança corporativa } \\
\text { da BM\&F. }\end{array}$ & \multirow{2}{*}{\multicolumn{2}{|c|}{$\begin{array}{l}\text { Liu e } \\
\text { Lu (2007); } \\
\text { Almeida- } \\
\text {-Santos et al. } \\
\text { (2011) }\end{array}$}} \\
\hline & 0 & $\begin{array}{l}\text { Se a empresa não está em um dos } \\
\text { níveis de governança corporativa } \\
\text { da BM\&F. }\end{array}$ & & \\
\hline \multirow{2}{*}{$\begin{array}{l}\text { Setor } \\
\text { (SET) }\end{array}$} & 1 & $\begin{array}{l}\text { Se a empresa pertence ao setor } \\
\text { regulado de Energia Elétrica. }\end{array}$ & \multirow{2}{*}{\multicolumn{2}{|c|}{$\begin{array}{l}\text { Kwag e } \\
\text { Small, (2007) }\end{array}$}} \\
\hline & 0 & $\begin{array}{l}\text { Se a empresa não pertence ao setor } \\
\text { regulado de Energia Elétrica. }\end{array}$ & & \\
\hline
\end{tabular}

Fonte: Os Autores (2017)

Dessa forma, a análise dos dados foi realizada a partir dos testes estatísticos de diferença de médias, correlação e regressão linear múltipla com dados em painel. Assim, tem-se que para a H1, H2, e H3, cujo objetivo é verificar o impacto da propriedade, gestão e controle familiar nas práticas de gerenciamento de resultados, a equação 2.

$$
\begin{gathered}
A D_{i t}=\beta_{0}+\beta_{1} F A M_{i t}+\beta_{2} T A M_{i t}+\beta_{3} A L A_{i t}+\beta_{4} R O E_{i t}+\beta_{5} R O A_{i t} \\
+\beta_{6} I D A_{i t}+\beta_{7} G O V_{i t}+\beta_{8} S E T_{i t}+\varepsilon_{i t}
\end{gathered}
$$


A tabulação das variáveis do modelo KS ocorreu por meio do software Microsoft Excel® e para a estimação dos acrruals discricionários, utilizou-se da regressão linear múltipla (Equação 1) realizada pelo software STATA®.

\section{DESCRIÇÃo E DISCUSSÃo dOS RESULTADOS}

Inicialmente, realizou-se a estimação dos accruals discricionários das empresas da amotra. Os accruals discricionários foram obtidos a partir da mensuração dos accruals totais e dos accruals estimados por meio da regressão linear múltipla (Equação 1), o qual representa o modelo Kang e Sivaramakrishnan (1995). Obtendo-se estes valores, procedeu-se com as estatísticas mais detidas a responder ao problema de pesquisa. Para tanto, desenvolveu-se a análise descritiva dos dados, análise da correlação entre as variáveis e, por fim, as regressões (Equação 2) que tiveram o objetivo de verificar se a propriedade, gestão e controle familiar influenciam a prática de gerenciamento de resultados destas empresas.

A Tabela 2 evidencia as estatísticas descritivas dos accruals discricionários e as variáveis dos modelos desta pesquisa. Além disso, também apresenta o Teste U de Mann-Whitney, cujo objetivo foi de verificar se existe diferença estatisticamente significativa das variáveis da pesquisa entre as empresas que tem a característica familiar (propriedade, gestão ou controle).

Através da Tabela 2, é possível observar no Painel A que a média dos accruals discricionários das empresas familiares, em valores absolutos, no período delimitado, foi de 0,1265. O Painel $B$, que representa as empresas cuja gestão é familiar, demonstram que em média os accruals discricionário são de 0,1283. Já no Painel C, empresas cujo controle é familiar, obtiveram valores médios de 0,1203 . Já no que se refere às empresas cuja característica não é familiar (propriedade, gestão e controle), demonstram valores médios de $0,1668,0,1648$ e 0,1624 , respectivamente.

Utilizando-se de abordagem semelhante para estimar o grau de gerenciamento de resultados, Vieira (2016) observou que a média dos accruals discricionários em empresas portuguesas foi de 0,08, enquanto González e García-Meca (2014), em empresas latino americanas, encontraram valores médios de 0,24. 
Tabela 2 - Estatística Descritiva

\begin{tabular}{|c|c|c|c|c|c|c|c|c|c|}
\hline \multicolumn{10}{|c|}{ PAINEL A: PROPRIEDADE FAMILIAR E NÃO FAMILIAR } \\
\hline & \multicolumn{4}{|c|}{ PROPRIEDADE FAMILIAR = 80} & \multicolumn{4}{|c|}{ PROPRIEDADE NÃO FAMILIAR = 127} & \multirow[b]{2}{*}{ U Teste } \\
\hline & Mínimo & Máximo & Média & DP & Mínimo & Máximo & Média & DP & \\
\hline$|\mathrm{AD}|$ & 0,00 & 1,42 & 0,1265 & 0,12946 & 0,00 & 8,94 & 0,1668 & 0,47321 & $0,004^{* *}$ \\
\hline TAM & 8,90 & 17,93 & 13,2532 & 1,75119 & 8,38 & 19,66 & 13,9307 & 2,14320 & $0,000^{* *}$ \\
\hline ALA & 0,01 & 16,01 & 0,8922 & 1,31414 & 0,03 & 16,34 & 0,9310 & 1,28732 & $0,013^{*}$ \\
\hline ROE & $-15,27$ & 4,95 & 0,0869 & 0,94471 & $-29,03$ & 19,32 & 0,1697 & 1,45308 & $0,012^{*}$ \\
\hline ROA & $-1,05$ & 1,01 & 0,0138 & 0,17351 & $-3,08$ & 2,34 & 0,0075 & 0,29440 & $0,015^{*}$ \\
\hline IDA & 0,00 & 24,52 & 14,9588 & 6,85138 & 0,00 & 24,77 & 13,8832 & 6,07100 & $0,003^{* *}$ \\
\hline GOV & 0,00 & 1,00 & 0,3000 & 0,45874 & 0,00 & 1,00 & 0,3858 & 0,48711 & $0,002^{* *}$ \\
\hline SET & 0,00 & 1,00 & 0,3125 & 0,46400 & 0,00 & 1,00 & 0,0551 & 0,22836 & $0,000^{* *}$ \\
\hline \multicolumn{10}{|c|}{ PAINEL B: GESTÃO FAMILIAR E NÃO FAMILIAR } \\
\hline & \multicolumn{4}{|c|}{ GESTÃO FAMILIAR = 77} & \multicolumn{4}{|c|}{ GESTÃO NÃO FAMILIAR = 130} & \\
\hline & Mínimo & Máximo & Média & DP & Mínimo & Máximo & Média & DP & U Teste \\
\hline$|\mathrm{AD}|$ & 0,00 & 1,42 & 0,1283 & 0,13107 & 0,00 & 8,94 & 0,1648 & 0,46798 & $0,002^{* *}$ \\
\hline TAM & 8,90 & 17,91 & 13,1864 & 1,69322 & 8,38 & 19,66 & 13,9546 & 2,15173 & $0,000^{* *}$ \\
\hline ALA & 0,01 & 16,01 & 0,8999 & 1,33530 & 0,03 & 16,34 & 0,9256 & 1,27513 & $0,011^{*}$ \\
\hline ROE & $-15,27$ & 4,95 & 0,0831 & 0,95511 & $-29,03$ & 19,32 & 0,1700 & 1,43922 & $0,010^{* *}$ \\
\hline $\mathrm{ROA}$ & $-1,05$ & 1,01 & 0,0138 & 0,17505 & $-3,08$ & 2,34 & 0,0077 & 0,29163 & $0,023^{*}$ \\
\hline IDA & 0,00 & 24,52 & 15,0055 & 6,88654 & 0,00 & 24,77 & 13,8804 & 6,06384 & $0,002^{* *}$ \\
\hline GOV & 0,00 & 1,00 & 0,2987 & 0,45818 & 0,00 & 1,00 & 0,3846 & 0,48682 & $0,002^{* *}$ \\
\hline SET & 0,00 & 1,00 & 0,3247 & 0,46876 & 0,00 & 1,00 & 0,0538 & 0,22586 & $0,000^{* *}$ \\
\hline
\end{tabular}

PAINEL C: CONTROLE FAMILIAR E NÃO FAMILIAR

\begin{tabular}{l|l|l|l|l|l|l|l|l|l}
\hline & \multicolumn{3}{|l|}{ CONTROLE FAMILIAR $=55$} & \multicolumn{3}{l|}{ CONTROLE NÃO FAMILIAR = 152} & \\
\hline & Mínimo & Máximo & Média & DP & Mínimo & Máximo & Média & DP & U Teste \\
\hline IAD I & 0,00 & 0,68 & 0,1203 & 0,11518 & 0,00 & 8,94 & 0,1624 &, 43718 & 0,178 \\
TAM & 8,90 & 17,89 & 13,3449 & 1,78092 & 8,38 & 19,66 & 13,7861 & 2,09777 & $0,000^{* *}$ \\
ALA & 0,01 & 16,01 & 0,9910 & 1,55206 & 0,03 & 16,34 & 0,8889 & 1,19169 & $0,007^{* *}$ \\
ROE & $-7,84$ & 3,94 & 0,1087 & 0,65316 & $-29,03$ & 19,32 & 0,1482 & 1,44249 & $0,008^{* *}$ \\
ROA & $-1,02$ & 1,01 & 0,0183 & 0,17761 & $-3,08$ & 2,34 & 0,0069 & 0,27716 & 0,102 \\
IDA & 0,00 & 24,52 & 15,1124 & 6,82411 & 0,00 & 24,77 & 14,0045 & 6,22091 & $0,007^{* *}$ \\
GOV & 0,00 & 1,00 & 0,2909 & 0,45487 & 0,00 & 1,00 & 0,3750 & 0,48439 & $0,006^{* *}$ \\
SET & 0,00 & 1,00 & 0,2909 & 0,45487 & 0,00 & 1,00 & 0,1053 & 0,30706 & $0,000^{* *}$ \\
\hline
\end{tabular}

** Significância ao nível de 0,01 - * Significância ao nível de 0,05;

$$
\text { Fonte: Os Autores (2017) }
$$

304 Organizações em contexto, São Bernardo do Campo, ISSNe 1982-8756 • Vol. 16, n. 31, jan.-jun. 2020 
Outro estudo, Jiraporn e DaDalt (2009), com empresas americanas, obtiveram valores médio próximos à 0,04. Esses resultados sugerem que países com participação relativamente concentrada e mercado de ações menos desenvolvidos apresentam níveis mais altos para o acréscimo discricionário e, por isso, menores níveis de qualidade de lucros do que economias com propriedade relativamente dispersa, forte proteção de investidores e grandes mercados de ações (FACCIO; LANG; YOUNG, 2001; LEUZ; NANDA; WYSOCKI, 2003; SALVATO; MOORES 2010).

Percebe-se que existe diferença estatisticamente significativa do grau de gerenciamento de resultados entre as empresas de propriedade e gestão familiar $(0,004$ e 0,002$)$, enquanto não foi possível observar essa mesma diferença com empresas cujo controle é familiar. Assim, é possível observar as empresas cuja propriedade, gestão e controle é familiar divulgam com melhor qualidade seus resultados comparado às empresas que não apresentam essa característica, entretanto, essa diferença não é significativa com as empresas de controle familiar.

Estes resultados sugerem as empresas com propriedade, gestão e controle familiar estão menos motivadas para as práticas de gerenciamento de resultados do que as não familiares, corroborando com os estudos de Prencipe, Markarian e Pozza (2008), Jiraporn e DaDalt (2009), Murphy, Johl e Khan (2010), Ghabdian, Attaran e Froutan (2012), Achleitner et al. (2014) e Vieira (2016).

Esta evidência é consistente com a hipótese de alinhamento (JENSEN; MECKLING, 1976; FAMA; JENSEN, 1983; GONZÁLEZ; GARCÍA-MECA, 2014), assim como a orientação a longo prazo das empresas familiares (ANDERSON; MANSI; REEB, 2003, GOMEZ-MEJIA et al., 2007; JIRAPORN; DADALT 2009; SALVATO; MOORES 2010) e o desejo de que estas empresas passem para as próximas gerações (BERRONE; CRUZ; GOMEZ-MEJIA, 2012; HASSO; DUNCAN 2013; ACHLEITNER et al., 2014), de modo a expandir o futuro cronograma do fluxo de lucros (VIEIRA, 2016).

Em comparação às empresas não familiares, uma empresa cuja propriedade, gestão ou controle é familiar está mais preocupada em acumular e preservar suas riquezas ao longo do tempo (VIEIRA, 2016). Consequentemente, haveria menos incentivos para obter 
benefícios à custa dos acionistas minoritários, o que melhora a qualidade dos resultados (Bona, Perez, \& Santana, 2008; Vieira, 2016).

A Tabela 2 traz também outros dados referentes às empresas da amostra. Observa-se que o tamanho (TAM) das empresas é semelhante nas empresas de propriedade $(13,25)$, gestão $(13,19)$ e controle familiar $(13,34)$. Estas empresas são, em média, relativamente menores às não familiares, sendo essa diferença estatisticamente significativa. A alavancagem (ALA) destas empresas também foi semelhante, com exceção da empresa de controle familiar que demonstrou alavancagem média de 0,99.

A rentabilidade, medida pelos índices de retorno sobre o patrimônio líquido (ROE) e sobre o ativo (ROA), também foram semelhantes entre os grupos de empresas com característica familiar, com exceção, novamente, das empresas cujo controle é familiar, em que foram relativamente maiores. Uma constatação observada, é de que na amostra obtida, as empresas de propriedade, gestão e controle familiar apresentaram ROE menores que as não familiares, entretanto o ROA se mostrou maior. Este resultado corrobora com os estudos de Jiraporn e DaDalt (2009), Almeida-Santos et al. (2013) e Vieira (2016).

Percebe-se que as empresas familiares são mais velhas que as suas contrapartes não familiares, de modo a indicar um maior tempo de inserção no mercado acionário da bolsa. Tal fato justifica essa orientação a longo prazo das empresas familiares, bem como elas buscarem expandir o futuro cronograma do fluxo de lucros (ANDERSON; MANSI; REEB, 2003, GÓMEZ-MEJÍA et al. 2007; JIRAPORN; DADALT, 2009; VIEIRA, 2016).

Das empresas familiares, observou-se que, em média, entre $30 \%$ e $29 \%$ delas estão contidas em algum dos níveis de governança corporativa da BM\&F, se mostrando em menores quantidades do que as não familiares, em que entre 39\% e 37\% apresentaram algum nível de governança. Outra constatação, é de que, em média, entre $32 \%$ e $29 \%$ das empresas familiares pertencem a algum dos setores regulados da economia, enquanto estes valores são significativamente menores nas empresas não familiares.

A Tabela 3 evidencia as correlações de Pearson entre as variáveis da amostra, comparando-se as empresas de propriedade, gestão e controle familiar e as não familiares. 


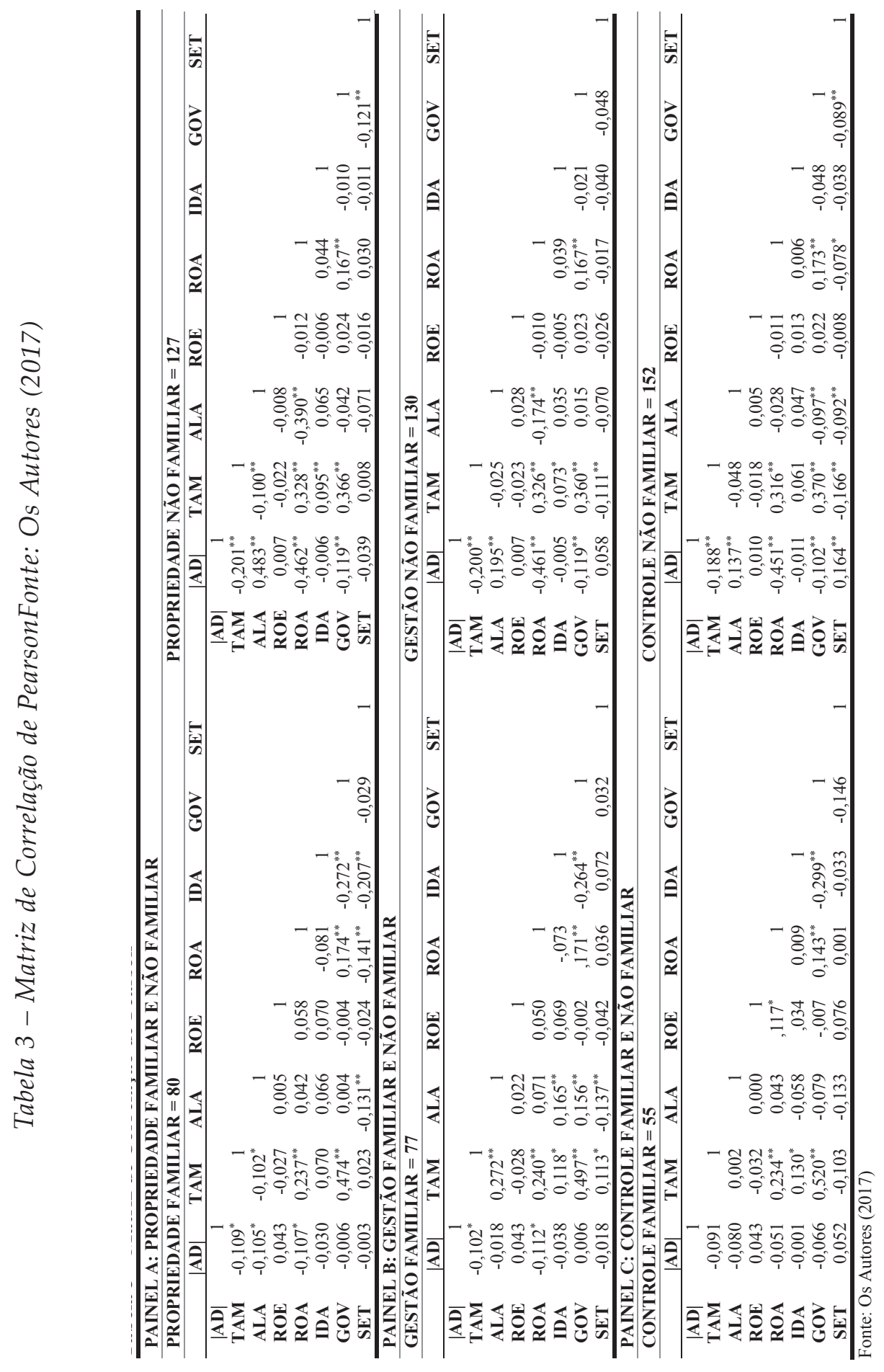


Os resultados dos testes de correlação permitem observar que para as empresas cuja propriedade é familiar, os accruals discricionários apresentaram correlação negativa o tamanho da empresa (TAM), alavancagem (ALA) e rentabilidade sobre o ativo (ROA), indicando que existe uma relação inversa entre os níveis de gerenciamento de resultados com estas variáveis. Já para as empresas de propriedade não familiar, a relação também foi negativa, com exceção da alavancagem, com as variáveis TAM, ROA e GOV.

Foram obtidos resultados semelhantes para as empresas de gestão familiar, as variáveis TAM e ROA apresentaram relação negativa com os accruals discricionários. As empresas cuja gestão não é familiar, apresentou correlação negativa com as variáveis TAM, ROA e GOV, e relação positiva com a ALA.

Nas empresas de controle familiar, as variáveis não apresentaram relações estatisticamente significativas com os accruals discricionários. Já as empresas de controle não familiar, apresentou novamente as mesmas relações das empresas anteriores não familiares, e mais a característica do setor regulado, em que se mostrou correlacionado positivamente com os níveis de gerenciamento de resultados.

No geral, percebe-se que os maiores coeficientes de correlação foram observados na relação da rentabilidade sobre o ativo (ROA) das empresas com os accruals discricionários. Além disso, também observa-se que a empresa pertencer a algum dos níveis de governança corporativa também tem relação com o tamanho da empresa.

A Tabela 4 apresenta os resultados estimados por meio do modelo de regressão linear com dados em painel, o qual buscou inferir se a característica familiar - FAM (propriedade - Pfam, gestão - Gfam e controle - Cfam) influencia os accruals discricionários.

O teste de Chow indicou que a hipótese nula de que todos os interceptos são iguais (POLS) fosse rejeitada, portanto, o mais recomendado é o modelo com efeitos fixos. $\mathrm{O}$ teste de Hausman também rejeitou a hipótese nula de que o modelo de correlação dos erros é adequado (efeitos aleatórios). Assim, com base nestes testes no caso deste estudo, o modelo com efeitos fixos é mais recomendado nas Equações 2, 3 e 4 e por isso foi utilizado nessa pesquisa. 
Tabela 4 - Influência da Propriedade, Gestão e Controle Familiar no Gerenciamento de Resultados das Empresas Brasileiras

\begin{tabular}{|c|c|c|c|}
\hline \multirow{4}{*}{$\begin{array}{l}\text { Variáveis indepen- } \\
\text { dentes }\end{array}$} & \multicolumn{3}{|c|}{ Variáveis dependentes } \\
\hline & $\begin{array}{l}\text { PAINEL A } \\
\text { Pfam (Eq.2) }\end{array}$ & $\begin{array}{l}\text { PAINEL B } \\
\text { Gfam (Eq.2) }\end{array}$ & $\begin{array}{l}\text { PAINEL C } \\
\text { Cfam (Eq.2) }\end{array}$ \\
\hline & $\begin{array}{l}\text { Coefic. } \\
\text { (sig. var) }\end{array}$ & $\begin{array}{l}\text { Coefic. } \\
\text { (sig.var) }\end{array}$ & $\begin{array}{l}\text { Coefic. } \\
\text { (sig.var) }\end{array}$ \\
\hline & Efeito Fixos & Efeito Fixos & Efeito Fixos \\
\hline FAM & $\begin{array}{l}-.0216439 \\
(0.234)\end{array}$ & $\begin{array}{l}-.0109874 \\
(0.575)\end{array}$ & $\begin{array}{l}-.0258571 \\
\left(0.089^{*}\right)\end{array}$ \\
\hline TAM & $\begin{array}{l}.0135862 \\
(0.284)\end{array}$ & $\begin{array}{l}.0137923 \\
(0.285)\end{array}$ & $\begin{array}{l}.0138466 \\
(0.265)\end{array}$ \\
\hline ALA & $\begin{array}{l}.1158383 \\
\left(0.010^{* * *}\right)\end{array}$ & $\begin{array}{l}.116409 \\
\left(0.010^{* * *}\right)\end{array}$ & $\begin{array}{l}.1162546 \\
\left(0.009^{* * *}\right)\end{array}$ \\
\hline ROE & $\begin{array}{l}.0032481 \\
(0.594)\end{array}$ & $\begin{array}{l}.0033394 \\
(0.586)\end{array}$ & $\begin{array}{l}.0034273 \\
(0.577)\end{array}$ \\
\hline ROA & $\begin{array}{l}-.3417615 \\
(0.119)\end{array}$ & $\begin{array}{l}-.341893 \\
(0.119)\end{array}$ & $\begin{array}{l}-.3417063 \\
(0.119)\end{array}$ \\
\hline IDA & $\begin{array}{l}-.0028889 \\
(\mathbf{0 . 0 2 0 * *})\end{array}$ & $\begin{array}{l}-.0029407 \\
\mathbf{( 0 . 0 1 9 * * )}\end{array}$ & $\begin{array}{l}-.0029223 \\
\left(0.017^{* *}\right)\end{array}$ \\
\hline GOV & $\begin{array}{l}-.0066676 \\
(0.593)\end{array}$ & $\begin{array}{l}-.0064303 \\
(0.602)\end{array}$ & $\begin{array}{l}-.0080128 \\
(0.530)\end{array}$ \\
\hline SET & $\begin{array}{l}-.0817663 \\
\left(0.000^{* * *}\right)\end{array}$ & $\begin{array}{l}-.0777983 \\
\left(0.000^{* * *}\right)\end{array}$ & $\begin{array}{l}-.079504 \\
(\mathbf{0 . 0 0 0 * * *})\end{array}$ \\
\hline CONST & $\begin{array}{l}-.0725395 \\
(0.710) \\
\end{array}$ & $\begin{array}{l}-.080276 \\
(0.687) \\
\end{array}$ & $\begin{array}{l}-.0777379 \\
(0.681) \\
\end{array}$ \\
\hline $\mathrm{R}^{2}$ & 0.2915 & 0.2910 & 0.2916 \\
\hline Sig. Do Modelo & 0.0000 & 0.0000 & 0.0000 \\
\hline Durbin-Watson & 1.634553 & 1.635316 & 1.694361 \\
\hline Mean VIF & 1.25 & 1.25 & 1.24 \\
\hline Teste BP/CW & 0.0000 & 0.0000 & 0.0000 \\
\hline Teste White & 0.0000 & 0.0000 & 0.0000 \\
\hline $\begin{array}{l}\text { Teste Breusch-Pa- } \\
\text { gan }\end{array}$ & 0.0000 & 0.0000 & 0.0000 \\
\hline F de Chow & 0.0000 & 0.0000 & 0.0000 \\
\hline Teste Hausman & 0.0064 & 0.0057 & 0.0061 \\
\hline № Observações & 1,242 & 1,242 & 1,242 \\
\hline
\end{tabular}

*** Significância ao nível de 0,01 - ** Significância ao nível de 0,05 - * Significância ao nível de 0,10

Fonte: Os Autores (2017) 
Observa-se que a modelagem das Equações 2, 3 e 4, composto de 1242 observações, foram significantes ao nível de 1\% para a amostra de empresas desta pesquisa. $\mathrm{O} \mathrm{R}^{2}$ que representa a proporção da variação amostral da variável dependente explicada pelas variáveis explicativas (WOOLDRIDGE, 2003), é de 29\% nas três equações. O modelo não apresenta problemas de autocorrelação, uma vez que o Durbin-Watson é 1.634553, 1.635316 e 1.694361, respectivamente, dentro do limite aceitável (HILL; JUDGE; GRIFFITHS, 2010). Não há problemas de multicolinearidade, conforme indica o teste VIF (1.25, 1.25 e $1.24<10$ ), medida de quanto a variância de cada coeficiente de regressão estimado aumenta devido à multicolinearidade (FÁVERO; BELFIORES; SILVA; CHAN, 2009). O teste de Breusch-Pagan/ Cook-Weisberg (0.0000 e 0.0000), e o teste de White (.0158 e 4.2e-04), indicam ter problemas de heterocedasticidade nos resíduos, justificando-se possivelmente pela existência de outliears em determinadas variáveis, gerando alguma discrepância entre os dados (GUJARATI, 2006), no entanto, para confiabilidade e robustez, aplicou-se a correção robusta de White.

No Painel A, observa-se que a propriedade familiar não influencia o gerenciamento de resultados das empresas, já que não foi estatisticamente significante. Assim, quando dois ou mais diretores de uma mesma família na administração da empresa ou dois mais diretores de uma mesma família que possuem ações da empresa - independentemente do número de ações (SEGURA; FORMIGONI, 2014), não é suficiente para caracterizar a relação destas empresas com o nível de gerenciamento de resultados, o que permite rejeitar a $H 1$.

No Painel B, a gestão familiar também não se mostrou estatisticamente significante, o que permitiu rejeitar a H2. Mostrando, mais uma vez, que quando as empresas familiares que possuem também pessoas da família nos cargos de comando da empresa, independentemente de haver controle acionário (SEGURA; FORMIGONI, 2014), não é suficiente para que as escolhas contábeis destes gestores sejam no sentido gerenciar seus resultados.

Entretanto, no Painel C, o controle familiar se mostrou estatisticamente significante, demonstrando que quando estas empresas além de serem classificadas como familiares, os acionistas familiares 
possuírem mais de $50 \%$ das ações da companhia, as escolhas dos gestores destas entidades tendem a reduzir o nível dos accruals discricionários. Assim, permitiu aceitar a $H 3$.

Assim, permite-se concluir que ter dois ou mais diretores da família na administração ou que possuem ações da empresa, assim como estes membros possuírem cargos de comando na empresa, não é suficiente para fazer com que as empresas gerenciem seus lucros (Segura, 2011), somente o controle é suficiente para caracterizar essa relação. Este resultado contrasta com resultados de estudos semelhantes encontrados em outros países, tais como Espanha (Mallorquí et al., 2007); Itália (PRENCIPE; MARKARIAN; POZZA, 2008); Hong Kong (JAGGI; LEUNG; GUL, 2009); Malásia (ISHAK et al. 2011); Austrália (SETIA-ATMAJA; HAMAM; TANEWSKI, 2011) e Brasil (ALMEIDA-SANTOS et al., 2013). Entretanto, corrobora com os estudos de Prencipe, Markarian e Pozza (2008), Jiraporn e DaDalt (2009), Murphy, Johl e Khan (2010), Ghabdian, Attaran e Froutan (2012) e Achleitner et al. (2014)

Adicionalmente, verificou-se que a alavancagem se mostrou com relação positiva com os accruals discricionários das empresas desta amostra. Assim como o estudo de Coelho e Lopes (2007), quanto maior a alavancagem da empresa, maior tende a ser seu nível de gerenciamento de resultados. Verificou-se, também, que o setor possuir relação negativa com os níveis de gerenciamento de resultados. As empresas que pertencem ao setor regulado de energia tendem a minimizar a manipulação de resultados da empresa, o que sugere a conclusão de que o órgão regulador inibe que estas empresas tenham maiores níveis de gerenciamento de resultados. (KWAG; SMALL, 2007; ALMEIDA-SANTOS et al., 2013).

Os resultados desta pesquisa são consistentes com o feito de alinhamento somente do controle familiar sobre as práticas de gerenciamento de resultados (WANG, 2006; MURPHY; JOHL; KHAN, 2010). As empresas de controle familiar têm menores níveis gerenciamento de resultados em comparação com as empresas de controle não familiar. Estas descobertas apoiam-se à noção de que o custo de agência é reduzido pela presença do controle familiar, o que faz com que entidades sofram problemas de agência menos graves do que as empresas não familiares em geral (MURPHY; JOHL; KHAN, 2010). 
A relação de agência que é mitiga pelo controle familiar levam a menores índices de manipulação de resultados por razões oportunistas e resulta em maior qualidade de resultados, já que as famílias possuem maior experiência em relação às operações da empresa para monitorar efetivamente as atividades das empresas (ALI; CHEN; RADHAKRISHNAN, 2007; CASCINO; PUGLIESE; MUSSOLINO; SANSONE, 2010; MURPHY; JOHL; KHAN, 2010).

As evidências dessa pesquisa corroboram com os pressupostos da Socioemotional Wealth Theory de que as empresas cujo os acionistas familiares detêm mais do que $50 \%$ das ações da companhia, preocupam-se na "sustentabilidade transgeracional", isto é, evitam ações que dificultam o valor futuro e tendem a preservar esse valor dentro da empresa manipulando o resultado de forma mais fraca do que as empresas de controle não familiar (GÓMEZ-MEJÍA et al., 2007; BERRONE; CRUZ; GOMEZ-MEJIA, 2012; ACHLEITNER et al., 2014).

\section{ConCluSÃo}

O objetivo deste estudo foi de verificar influência da propriedade, gestão e controle familiar na prática de gerenciamento de resultados das empresas brasileiras listadas na B3. O estudo surge da necessidade de avaliar as empresas familiares sob diferentes óticas (propriedade, gestão e controle familiar) e verificar a relação destas com as práticas de gerenciamento de resultados. Para tanto, adotou-se uma abordagem quantitativa, utilizando-se do modelo de Kang e Sivaramakrishnan (1995) para mensurar os accruals discricionários, realizando-se a análise a partir de testes de estatística descritiva, correlação e regressão linear múltipla.

Os testes realizados puderam verificar que, em média, os accruals discricionários das empresas de propriedade, gestão e familiar são menores que suas contrapartes respectivas não familiares. No caso brasileiro destas empresas, observa-se a média das acumulações discricionárias das empresas familiares é maior do que em países cuja propriedade é relativamente dispersa, existe forte proteção de investidores e tenham grandes mercados de ações (FACCIO; LANG; YOUNG, 2001; LEUZ; NANDA; WYSOCKI, 2003).

Percebe-se que existe diferença estatisticamente significativa 
do grau de gerenciamento de resultados entre as empresas de propriedade e gestão familiar, não observando-se essa mesma relação em empresas de controle familiar. Estes resultados são consistentes com a hipótese de alinhamento (JENSEN; MECKLING, 1976; FAMA; JENSEN, 1983; GONZÁLEZ; GARCÍA-MECA, 2014), assim como a orientação a longo prazo das empresas familiares (ANDERSON; MANSI; REEB, 2003; GÓMEZ-MEJÍA et al. 2007; JIRAPORN; DADALT, 2009) e o desejo de que estas empresas passem para as próximas gerações (BERRONE; CRUZ; GOMEZ-MEJIA, 2012; HASSO; DUNCAN 2013; ACHLEITNER et al., 2014), expandindo o futuro cronograma do fluxo de lucros (VIEIRA, 2016).

O tamanho das empresas de propriedade, gestão e controle familiar são semelhantes, mas menores que as não familiares. A alavancagem destas entidades se mostrou da mesma forma que a variável anterior, com exceção das empresas de controle familiar. A rentabilidade sobre o patrimônio líquido é menor nas empresas familiares, enquanto a rentabilidade sobre o ativo é maior para este mesmo grupo de empresas, realidade também observada nos estudos de Jiraporn e DaDalt (2009), Almeida-Santos et al. (2013) e Vieira (2016). As empresas familiares são mais velhas que as suas contrapartes não familiares, o que justifica a orientação de longo prazo destas entidades e a ideia de que elas buscam expandir o futuro cronograma do fluxo de lucros (ANDERSON; MANSI; REEB, 2003; GOMEZ-MEJIA et al. 2007; JIRAPORN; DADALT 2009; VIEIRA, 2016).

Pelas análises de regressão foi possível observar a importância de segregar as empresas pela propriedade, gestão e controle familiar. Os resultados demonstraram que a propriedade e gestão familiar são características que não são suficientes para caracterizar a relação com as práticas de gerenciamento de resultados, o que levou a rejeição das hipóteses $H 1$ e $H 2$, enquanto o controle familiar se mostrou estatisticamente significante e negativo, confirmado o que se esperava, o que permitiu aceitar $H 3$.

Os resultados dos testes realizados contrastam com estudos semelhantes realizados em outros países, tais como Espanha (MALLORQUÍ et al., 2007); Itália (PRENCIPE; MARKARIAN; POZZA, 2008); Hong Kong (JAGGI; LEUNG; GUL, 2009); Malásia (Ishak et al. 2011); Austrália (SETIA-ATMAJA; HAMAM; TANEWSKI, 2011) 
e Brasil (Almeida-Santos et al., 2013). Entretanto, nossas evidências são sustentadas em outros estudos, na teoria da agência e na Socioemotional Wealth Theory (PRENCIPE; MARKARIAN; POZZA, 2008; JIRAPORN; DADALT, 2009; MURPHY; JOHL; KHAN, 2010; GHABDIAN; ATTARAN; FROUTAN, 2012; PAIVA; LOURENÇO, 2013; ACHLEITNER et al., 2014)

As descobertas desta pesquisa apoiam-se à noção de que o custo de agência é reduzido pela presença do controle familiar (MURPHY; JOHL; KHAN, 2010), levando a menores índices de manipulação de resultados por razões oportunistas e melhor qualidade dos resultados, o controle familiar indica que as operações da empresa são realizadas por gestores com maior experiência, permitindo o adequado monitoramento das atividades das empresas (ALI; CHEN; RADHAKRISHNAN, 2007; CASCINO et al., 2010; MURPHY; JOHL; KHAN, 2010).

Uma das contribuições dessa pesquisa é no sentido de perceber que empresas cujo os acionistas familiares detêm mais do que $50 \%$ das ações da companhia (controle familiar), evitam ações que prejudiquem o valor futuro e tendem, por isso, a preservar o valor da empresa manipulando menos o resultado dos que as empresas de controle não familiar (GÓMEZ-MEJÍA et al., 2007; BERRONE; CRUZ; GOMEZ-MEJIA, 2012; ACHLEITNER et al., 2014).

Outra contribuição da pesquisa é por verificar a realidade das empresas familiares brasileiras no que se refere às práticas de gerenciamento de resultados sob três diferentes óticas - propriedade, gestão e controle familiar. Essa característica foi importante pois possibilitou visualizar a influência da característica familiar na dominação das escolhas contábeis feitas por empresas que apresentam essas três diferentes estruturas.

Entre as limitações dessa pesquisa destaca-se o fato de ter escolhido apenas as empresas brasileiras listadas na B3, o período delimitado e as variáveis de controle utilizadas. Apesar disso, espera-se que os resultados não sejam diferentes em outros períodos e com outras variáveis, a não ser com a amostra, já que esta é uma característica específica de cada país e que permite diferentes discussões.

Como sugestão para pesquisas futuras, tem-se, justamente, avançar nas próprias limitações da pesquisa. Outra sugestão, é no 
sentido de continuar as discussões a respeito deste tema, principalmente sob a ótica da Socioemotional Wealth Theory, visto que se mostrou uma lacuna nas pesquisas nacionais e que também demanda discussão ao nível internacional.

\section{REFERÊNCIAS}

ACHLEITNER, A. K.; GÜNTHER, N.; KASERER, C.; SICILIANO, G. Real earnings management and accrual-based earnings management in family firms. European Accounting Review, v. 23, n. 3, p. 431-461, 2014.

AHMED, A. S.; TAKEDA, C.; THOMAS, S. Bank loan loss provisions: a reexamination of capital management, earnings management and signaling effects. Journal of Accounting and Economics, v. 28, n. 1, p. 1-25, 1999.

ALDRIGHI, D. M.; MAZZER NETO, R. Estrutura de propriedade e de controle das empresas de capital aberto no Brasil. Revista de Economia Política, v. 25, n. 2, p. 115-137, 2005.

ALI, A.; CHEN, T.; RADHAKRISHNAN, S. Corporate disclosures by family firms. Journal of accounting and economics, v. 44, n. 1, p. 238-286, 2007.

ALMEIDA-SANTOS, P. S.; DANI, A. C.; MACHADO, D. G.; KRESPI, N. T. Influence of family control in the practice of earnings management: the case of open Brazilian companies. Management Research: The Journal of the Iberoamerican Academy of Management, v. 11, n. 1, p. 77-99, 2013.

ANDERSON, R. C.; MANSI, S. A.; REEB, D. M. Founding family ownership and the agency cost of debt. Journal of Financial economics, v. 68, n. 2, p. 263-285, 2003.

ANDERSON, R. C.; REEB, D. M. Board composition: Balancing family influence in S\&P 500 firms. Administrative science quarterly, v. 49, n. 2, p. 209-237, 2004.

BERLE, A.; MEANS, G. The Modern Corporation and Private Property Macmillan. New York, 1932.

BERRONE, P.; CRUZ, C.; GOMEZ-MEJIA, L. R. Socioemotional wealth in family firms: Theoretical dimensions, assessment approaches, and agenda for future research. Family Business Review, v. 25, n. 3, p. 258-279, 2012.

BONA, C.; PEREZ, J.; SANTANA, D. Family control and earnings management. Spanish Accounting Review, v. 10, n. 1, p. 11-34, 2008.

CASCINO, S.; PUGLIESE, A.; MUSSOLINO, D.; SANSONE, C. The influence of family ownership on the quality of accounting information. Family Business Review, v. 23, n. 3, p. 246-265, 2010.

COELHO, A. C. D.; LOPES, A. B. Avaliação da prática de gerenciamento de resultados na apuração de lucro por companhias abertas brasileiras conforme seu grau de alavancagem financeira. Revista de Administração Contemporânea, v. 11, n. SPE2, p. 121-144, 2007. 
CUPERTINO, C. M.; MARTINEZ, A. L. Qualidade da auditoria e earnings management: risk assessment através do nível dos Accruals Discricionários. Contabilidade Vista \& Revista, v. 19, n. 3, 2008.

DECHOW, P. M.; SLOAN, R. G.; SWEENEY, A. P. Causes and consequences of earnings manipulation: An analysis of firms subject to enforcement actions by the SEC. Contemporary accounting research, v. 13, n. 1, p. 1-36, 1996.

FACCIO, M.; LANG, L. H.; YOUNG, L. Dividends and expropriation. American Economic Review, p. 54-78, 2001.

FAMA, E. F.; JENSEN, M. C. Separation of ownership and control. The journal of law and Economics, v. 26, n. 2, p. 301-325, 1983.

FASOLIN, L. B.; KLANN, R. C. Gerenciamento De Resultados Por Accruals Específicos em Empresas Familiares Brasileiras. In Anais do IX Congresso Anpcont, 2015.

FÁVERO, L. P.; BELFIORE, P.; SILVA, F. D.; CHAN, B. L. Análise de dados: modelagem multivariada para tomada de decisões. Rio de Janeiro: Elsevier, 2009.

FIEGENER, M. K. Locus of ownership and family involvement in small private firms. Journal of Management Studies, v. 47, n. 2, p. 296-321, 2010.

GHABDIAN, B.; ATTARAN, N.; FROUTAN, O. Ownership structure and earnings management: Evidence from Iran. International Journal of Business and Management, v. 7, n. 15, p. 88, 2012.

GILSON, R. J.; GORDON, J. N. Controlling controlling shareholders. University of Pennsylvania Law Review, v. 152, n. 2, p. 785-843, 2003.

GÓMEZ-MEJÍA, L. R.; HAYNES, K. T.; NÚÑEZ-NICKEL, M.; JACOBSON, K. J.; MOYANO-FUENTES, J. Socioemotional wealth and business risks in family-controlled firms: Evidence from Spanish olive oil mills. Administrative science quarterly, v. 52, n. 1, p. 106-137, 2007.

GONZÁLEZ, J. S.; GARCÍA-MECA, E. Does corporate governance influence earnings management in Latin American markets? Journal of Business Ethics, v. 121, n. 3, p. 419-440, 2014.

GUJARATI, D. Econometria Básica (4a ed.). São Paulo: Campus, 2006.

HASSO, T.; DUNCAN, K.. Valuation of family firms: the limitations of accounting information. Australian Accounting Review, v. 23, n. 2, p. 135-150, 2013.

HEALY, P. M.; WAHLEN, J. M. A review of the earnings management literature and its implications for standard setting. Accounting horizons, v. 13, n. 4, p. 365-383, 1999.

HILL, C.; JUDGE, G. G.; GRIFFITHS, W. E. Econometria (3a ed.). São Paulo: Saraiva, 2010.

Ishak, I., Haron, M. N., Nik-Salleh, N. M., \& Abdul-Rashid, A. (2011). Family control and earnings management: Malaysia evidence. International Proceedings of Economics Development and Research, 22, 82-86.

JAGGI, B.; LEUNG, S.; GUL, F. Family control and earnings management: Malaysia evidence. International Proceedings of Economics Development and Research, v. 22, p. 82-86, 2011. 
JENSEN, M. C.; MECKLING, W. H. Theory of the firm: Managerial behavior, agency costs and ownership structure. Journal of financial economics, v. 3, n. 4, p. 305-360, 1976.

JIRAPORN, P.; DADALT, P. J. Does founding family control affect earnings management?. Applied Economics Letters, v. 16, n. 2, p. 113-119, 2009.

JONES, J. J. Earnings management during import relief investigations. Journal of accounting research, p. 193-228, 1991.

KANG, S.; SIVARAMAKRISHNAN, K. Issues in testing earnings management and an instrumental variable approach. Journal of accounting Research, p. 353-367, 1995.

KWAG, S. A.; SMALL, K. The impact of regulation fair disclosure on earnings management and analyst forecast bias. Journal of Economics and Finance, v. 31, n. 1, p. 87-98, 2007.

LEAL, R. P. C.; SILVA, A. L. C.; VALADARES, S. M. Estrutura de controle das companhias brasileiras de capital aberto. Revista de Administração Contemporânea, v. 6, n. 1, p. 7-18, 2002.

LEUZ, C.; NANDA, D.; WYSOCKI, P. D. Earnings management and investor protection: an international comparison. Journal of financial economics, v. 69, n. 3, p. 505-527, 2003.

LI, I.; HUNG, J. The moderating effects of family control on the relation between managerial overconfidence and earnings management. Review of Pacific Basin Financial Markets and Policies, v. 16, n. 02, p. 1350010, 2013.

LIU, Q.; LU, Z. J. Corporate governance and earnings management in the Chinese listed companies: A tunneling perspective. Journal of Corporate Finance, v. 13, n. 5, p. 881-906, 2007.

LONGENECKER, J. G.; MOORE, C. W.; PETTY, J. W. Administração de Pequenas Empresas. São Paulo: Thomson Learning, 2007.

MALLORQUi, M. V. R.; ALEMÁN, J. P.; SÁNCHEZ, C. B. MARTIN, D. J. S. Calidad del resultado y propriedad institucional. Conocimiento, innovación y emprendedores: camino al futuro, p. 323-339, 2007.

MARTINEZ, A. L. “Gerenciamento" dos resultados contábeis: estudo empírico das companhias abertas brasileiras. 2001. Tese de Doutorado, Universidade de São Paulo, São Paulo, SP, 2002.

MURPHY, G. F.; JOHL, S.; KHAN, A. Family Firms and Earnings Quality: Evidence from Top 500 ASX Companies. 2010. Working Paper, SSRN: http://ssrn. com/abstract= 1717196.

PAULO, E. Manipulação das informações contábeis: uma análise teórica e empírica sobre os modelos operacionais de detecção de gerenciamento de resultados. 2007. Tese de Doutorado, Universidade de São Paulo, São Paulo, SP, 2007.

PORTA, R.; LOPEZ-DE-SILANES, F.; SHLEIFER, A. Corporate ownership around the world. The journal of finance, v. 54, n. 2, p. 471-517, 1999.

PRENCIPE, A.; MARKARIAN, G.; POZZA, L. Earnings management in family firms: Evidence from R\&D cost capitalization in Italy. Family Business Review, v. 21, n. 1, p. 71-88, 2008.

SALVATO, C.; MOORES, K. Research on Accounting in Family Firms: Past Accomplishments and Future Challenges. Family Business Review, v. 23, n. 3, p. 193-215, 2010. 
SCHULZE, W. S.; LUBATKIN, M. H.; DINO, R. N.; BUCHHOLTZ, A. K. Agency relationships in family firms: Theory and evidence. Organization science, v. 12, n. 2, p. 99-116, 2001.

SEGURA, L. A influência da gestão e do controlo de familiares e do fundador sobre o endividamento das empresas abertas brasileiras: Evidencias Empíricas. Tese de Doutoramento da Universidade Presbiteriana Mackenzie, 2012.

SEGURA, L. C.; FORMIGONI, H. Influence of control and family management in the indebtedness of Brazilian open business: A quantitative study. BBR-Brazilian Business Review, v. 11, n. 6, 2014.

SETIA-ATMAJA, L.; HAMAN, J.; TANEWSKI, G. The role of board independence in mitigating agency problem II in Australian family firms. The British Accounting Review, v. 43, n. 3, p. 230-246, 2011.

THOMSEN, S.; PEDERSEN, T. European ownership concentration: causes and consequences. Institute of International Economics and Management. Copenhagen: Copenhagen Business School, 1997.

VIEIRA, E. F. S. Earnings Management in Public Family Firms under Economic Adversity. Australian Accounting Review, v. 26, n. 2, p. 190-207, 2016.

WANG, D. Founding family ownership and earnings quality. Journal of accounting research, v. 44, n. 3, p. 619-656, 2006.

WOOLDRIDGE, J. M. Cluster-sample methods in applied econometrics. The American Economic Review, v. 93, n. 2, p. 133-138, 2003.

YOUNG, M. N.; PENG, M. W.; AHLSTROM, D.; BRUTON, G. D.; JIANG, Y. Corporate governance in emerging economies: A review of the principal-principal perspective. Journal of management studies, v. 45, n. 1, p. 196-220, 2008.

Recebido em: 31-5-2019

Aprovado em: 17-11-2020

Avaliado pelo sistema double blind review.

Disponível em http://mjs.metodista.br/index.php/roc 